\title{
Development of New Products of Summer Women Trousers
}

\author{
Zhijuan Tang \\ College of Art and Appareluages, Tianjin Polytechnic University, Tianjin 300160, China \\ E-mail: aina0510@yahoo.cn
}

\begin{abstract}
In garment production enterprises, researches on and development of women's trousers play significant role. As an important component of summer women's garments, women's trousers shall be attached with significance. Garment enterprises concern about how to develop new products so as to obtain more profits. New products' development strategy, task plan book, product positioning, pattern and design, samples manufacturing and evaluation shall all be taken into consideration in women's trousers development process.
\end{abstract}

Keywords: Garment, Women's trousers, Product development

\section{Development strategy for summer women's trousers}

\subsection{Investigation and research on women's trouser market}

Before the decision on development of new women's trousers is made, the aim of the development must be clearly fixed and we shall approximately fix the products' position in the market. Subsequently, the existing women's trouser market shall be investigated so as to understand the existing problems in the market and to search for the standing point for the development of your own products. The following issues shall be resolved when conducting market investigation and research.

1.1.1 Who are the consumers? What are the characteristics of such consumption group?

Summer women's trouser is a rather vague and general concept. The key issue is that which group the development aims at. We need to do particular investigation and analysis so as to determine what kinds of products shall be developed, trousers for mature ladies or for young ladies, or professional or leisure trousers.

The next step is to determine the class of your products. The products' class must be clearly fixed at the primary stage. If the women's trousers are of middle or high class, to some extent, all professional women workers will have their own requirements on garments. If the trousers are for young ladies, the quality of the trousers will be not as high as professional trousers whilst pattern changes are the main characteristics and the detailed ornaments and the collocation of color shall be emphasized.

Seeing form these details, we must conduct investigation on women through market in order to understand women's different requirements on trousers and the preference of women of different ages when choosing women's trousers and skirts.

1.1.2 What shall be given preliminary attention when developing new products?

Different from garments of other seasons, summer women's trousers have their own characteristics. Summer is a hot season. The first line requirement of people when choosing a garment for summer is that the garment shall be pleasantly cool, convenient, slinky and decent. The color of a garment cannot be neglected, either. In summer, people's requirement on color is very strict. It is found through investigation that when people are choosing a garment, the all-important element is the visual selection while color is the strongest element in visual impact.

1.1.3 What to choose for women trousers' style, professional or leisure?

When choosing women trousers' style, one must comprehensively understand women's requirements on summer women's trousers. Different occasions require different garments. Groups of different ages lay different requirements too. In addition, we should also take into account whether we should focus on professional trousers or leisure trousers.

Aiming at the above mentioned three questions, we need to conduct market investigation on women's trousers in order to understand the market, the target groups and the specific requirements of people on garments. The appendix is a market investigation questionnaire (please refer to the appendix) on summer women's trouser market.

\subsection{Analysis on fashion trend}

With the improvement of living, the requirements of people on garments gradually advance. The garments need to be 
slinky, comfortable and not harmful to the environment. What is more, the garments shall be elegant, soft, blandly colored, designed in simple and vivid style and teemed with modern sense.

Garments for young ladies should highlight free personality. The styles of garments for young ladies shall be finely designed so as to pursue simplicity and immanency. What garments for young ladies pursue is the decent and linear simple beauty, classic and fashionable style, elegance and sophistication revealed by unadorned coziness, and grace reflected in the search for low status.

Fashionable materials adopt natural fiber textiles, especially cotton textiles. Elastic fiber is added into those textiles. Spandex cotton textile is well welcomed in summer because it feels comfortable when wearing spandex cotton textile and it is easy for spandex cotton textile to keep their shapes. Other chemical textiles, such as the mixed fiber textile of terylene with cotton and acrylic with cotton, are also suitable for wearing in summer, which overcomes the defects of terylene and acrylic.

From the angle of fashion, the popular color and overall fashion trend of each year is just one aspect. Materials, decorations, ornaments, and architectures are also parts of fashion, especially color. Popular color of each year varies. However, usually several colors are keys in the fashion and there are other assisting colors.

\section{Task plan book for women's trouser design}

When making out design task book for new women's trousers, we shall include the following main contents:

2.1 Regulations on the styles of garment patterns; main structure and specification parameters; the wear functions and appearance quality of the garment, etc.;

2.2 The expected technical and economic indicators, such as planned investment costs, sale amount, price strategy, profit amount, and investment return period;

2.3 Product development modes and analysis, such as development expenses, development conditions, technical talents needed, development period and date the completion.

\section{Product design methods}

\subsection{Shape and structure method}

First, we should design the shapes and structures for our products, such as, seven-tenth wide lag boot trousers, nine-tenth small platelet trousers, ten-tenth middle canister trousers, slight trumpet long trousers. When the shape and structure are fixed, it will be much easier to make designs according to the requirements.

\subsection{Color restriction method}

First, the main colors and matching colors of works under design shall be given restriction. For example, black, deep blue and deep coffee is the color scheme and white of a style, stone, light blue is group color for the style. Therefore, we have to make choice according to the color restriction.

\subsection{Material restriction method}

First, the materials shall be restricted, such as jeans, corduroy, filament, and TR. Then in the design, we have to choose styles and matching materials that can go with this kind of materials. We can also make an investigation at the market so as to have a better understanding and to avoid the condition where the style does not suit the materials.

\subsection{Track method}

We can use one object as a stereotype, based on which we can deduce relevant forms of the object and apply them into the development of series styles. This method is suitable for quick design of large amount.

\section{Product design of summer women's trousers}

Women's trousers of a new season will usually be different from other seasons. Oliver Theyskens of Rochas once said that, "women' trousers must be sexy. Not like men's suits which should be erect and handsome, women's trousers can be casual and informal". New women's trousers pursue multi-elements in style and materials. They can be made of silk, jeans, cotton or flax; they can be long or short trousers, wide leg trousers, skintight sleeping trousers, high waist or low waist trousers. The followings are some trouser styles that are popular in summer:

Skintight thesium elder sister trousers: they are short pants to the up two or three centimeters of knee. Their styles are casual. At the beginning, men at Bermudas island wore such pants with half-length socks. Therefore, they got such a name. The skintight thesium trousers resembles the short pants that cyclists wear. Skintight thesium short pants fit well in the membrane. Going with navy suit, they are very fashionable and lively.

Hot pants: hot pants are as short as to the very top of the leg and skintight. As fashionable garments, hot pants can best reflect the body curve. For healthy women who have perfect body shape, hot pants are the best choice for them to show their magic figures. What is more, hot pants can make people look exquisite and full of energy. It is better to have some 
ornaments of design sense on the hot pants, such as nail flowers, embroider, rivets and printed flowers. Short jacketing, such as gallus waistcoats and short T-shirts, can go with hot pants, which will bring more charms.

Seven-tenth and nine-tenth trousers: they will not be so stubborn as long trousers and will not be too active like short trousers, which not only meets the taste of lively and cute young girls but also can enable women at the age around 40 to be fashionable and energetic. Such trousers meet demands of women at various ages.

\section{Analysis on style}

It is better to compare the popular colors of the year with that of previous years and find out the particularity of the popular colors of the year. The summer women's garments are mainly in light colors. Young ladies' garments are in active and cut color. Red, green and blue are what people prefer in summer.

With regard to long leisure women's trousers, we can use slide fastener in the middle of the trousers' leg to decorate the trousers. By this way, the trousers can be both long trousers and short trousers. At the same time, the design on details can be complicated. The trousers' legs can be divided. However, such division is just for decoration, which can beautify the shape of the trousers. On the both sides of the trousers, outer pockets can be used, which can bring movement sense. A belt can be added as decoration, which will be special and break routine rules.

It is cool and convenient to wear short trousers in summer. Such young ladies' garment will be well welcomed. When taking on such garment, the young ladies will look pure, lively, and cute. To make slight changes on such trousers will bring a series of different styles.

The development space of women's nine-tenth to five-tenth trousers is big. The design mainly makes use of embroidery and folk pictures. To broider different pictures onto garments of the same style will also generate different style and effect.

\section{Sample manufacturing and evaluation}

Garment designers draw pictures according to the ideas of development departments. At this stage, the products are at the artistic works. Only though specific materials and needlework can the specific visual effect be represented. By sample manufacturing, a correspondent report on the sample manufacturing can be given. The contents of the report shall include whether the shape of the product complies with what is designed in the design plan book, opinions on the improvement of the samples, and the comparison of the sample with competitors on market.

After the sample of the new styles is manufactured, the technology department will comprehensively evaluate and appraise the shape effect, technology performance ad economy effect of the new products. The samples shall be appraised from the following three aspects: firstly, whether the design materials are integrated; whether the sample complies with technological regulations; secondly, whether the manufacturing quality and garment material are proper; whether the labor hours are recorded exactly and entirely; thirdly, the effect, structure, technique property and economic property of the samples will be evaluated and given conclusion and opinions on improving the product will be provided. Then, the sample appraisal certificate will be filled in, where the appraisers shall give advice on whether the new products could be manufactured in limited amount.

\section{References}

Ma, Dali. (2003). Merchandize Enterprise Planning. Beijing: China Textile Press.

Xiao, Shitang, Wang, Yufang \& Hao, Feng. (2002). Development and Design of New Products and Statistic Technology. Beijing: China Metrology Publishing House.

Zhu, Xiuli, He, Ailin \& Yang, Qiuju. (2007). A probe into planning for the development of garment products. Zhejiang Science and Technology Paper, 2007 (9). 